\title{
Delphinid whistle production and call matching during playback of simulated military sonar
}

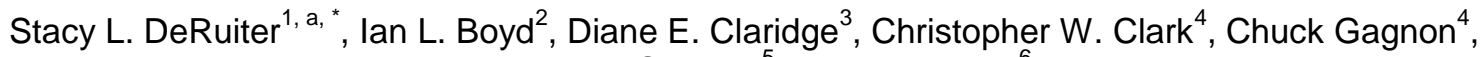 \\ Brandon L. Southall ${ }^{5}$, Peter L. Tyack ${ }^{6}$
}

\footnotetext{
${ }^{1}$ Service Acoustique et Sismique, Ifremer Centre de Brest, BP 70, 29280 Plouzané, France

${ }^{2}$ Scottish Oceans Institute, East Sands, University of St Andrews, St Andrews, Fife KY16 8LB, United Kingdom

${ }^{3}$ Bahamas Marine Mammal Research Organisation, PO Box AB-20714, Marsh Harbour, Abaco, Bahamas

${ }^{4}$ Cornell Lab of Ornithology, 159 Sapsucker Woods Road, Ithaca, New York 14850, U.S.A.

${ }^{5}$ SEA, Inc., 911 Center Street, Suite B, Santa Cruz, California 95060, U.S.A.

${ }^{6}$ Scottish Oceans Institute, East Sands, University of St Andrews, St Andrews, Fife KY16 8LB, United Kingdom.

a Present address: Centre for Research into Ecological and Environmental Modelling, The Observatory, Buchanan Gardens, University of St Andrews, St Andrews, Fife KY16 9LZ, United Kingdom.
}

*: Corresponding author : Stacy L. DeRuiter, email address : stacy deruiter@yahoo.com

\begin{abstract}
:
In 2007 and 2008, controlled exposure experiments were performed in the Bahamas to study behavioral responses to simulated mid-frequency active sonar (MFA) by three groups of odontocetes: false killer whales, Pseudorca crassidens; short-finned pilot whales, Globicephala macrorhynchus; and melon-headed whales, Peponocephala electra. An individual in each group was tagged with a Dtag to record acoustic and movement data. During exposures, some individuals produced whistles that seemed similar to the experimental MFA stimulus. Statistical tests were thus applied to investigate whistle-MFA similarity and the relationship between whistle production rate and MFA reception time. For the false killer whale group, overall whistle rate and production rate of the most MFA-like whistles decreased with time since last MFA reception. Despite quite low whistle rates overall by the melonheaded whales, statistical results indicated minor transient silencing after each signal reception. There were no apparent relationships between pilot whale whistle rates and MFA sounds within the exposure period. This variability of responses suggests that changes in whistle production in response to acoustic stimuli depend not only on species and sound source, but also on the social, behavioral, or environmental contexts of exposure.
\end{abstract}

Keywords : noise ; Sonar ; mid-frequency sonar ; whistle ; behavioral effects ; sound production ; Pseudorca crassidens ; Globicephala macrorhynchus ; Peponocephala electra ; false killer whale ; pilot whale ; melon-headed whale 
Anthropogenic sound in the ocean is recognized as a potential threat to marine mammal

44 welfare and population sustainability (National Research Council 2005, Southall et al. 2007). As

45 a specific example, a link has been observed between the operation of powerful, military, mid-

46 frequency sonar systems (MFA, operating at about 1 to $10 \mathrm{kHz}$ ) and atypical mass strandings and

47 deaths of cetaceans in certain conditions; several species of beaked whales are particularly

48 affected (Frantzis 1998, Simmonds and Lopez-Jurado, 1991, Balcomb and Claridge, 2001, Evans

49 and England, 2001, Fernández et al., 2005, Hildebrand, 2005, Parsons et al., 2008, Filadelfo et

50 al., 2009). Research to date suggests that behavior changes prompted by the sonar are probably

51 one component of the mechanism linking sonar to strandings (Houser et al. 2001, Cox et al.

52 2006, Zimmer and Tyack 2007), so several studies have focused on the behavioral responses of

53 cetaceans to military sonars (Tyack et al. 2011, Kvadsheim et al. 2009). Here, we present data

54 from the Behavioral Response Study 2007-2008 (BRS 07-08) (Tyack et al. 2011) in which

55 beaked whales and other toothed whales were intentionally exposed to controlled, simulated

56 MFA sonar signals.

$57 \quad$ Silencing and avoidance are among the expected responses of marine mammals to

58 military MFA sonar, especially for species like beaked whales that rely on acoustic and

59 behavioral crypsis to avoid threats (Johnson et al. 2004, Zimmer et al. 2005, Tyack et al. 2006)

60 and are thus particularly wary of acoustic stimuli (Barlow and Cameron 2003, Carretta et al.

61 2008). Indeed, beaked whales respond to anthropogenic noise with premature cessation of

62 echolocation clicks and prolonged ascent during foraging dives (Aguilar Soto et al. 2006, Tyack

63 et al. 2011). Porpoises and other toothed whales that produce narrow-band, high-frequency 
64 echolocation clicks may have similar risk-avoidance strategies (Madsen et al. 2005a, Morisaka 65 and Connor 2007).

However, many delphinid species are highly social. They live in relatively large groups,

67 make frequent use of sound to communicate in both affiliative and agonistic contexts, and may

68 rely in some contexts on social defenses against predators or conspecific competitors rather than

69 fleeing threats or employing acoustic crypsis (Tyack 2000). It is possible that these species

70 respond to acoustic stimuli by modifying their sound production or social behavior, for example

71 by changing group cohesion or whistle production patterns (Lesage et al. 1999).

72 A change in whistle production patterns could involve whistling in response to the sound

73 stimulus, perhaps even imitating it. In contrast to most mammals, there is abundant evidence that

74 dolphins can produce rare spontaneous or consistent trained imitations of anthropogenic

75 (Caldwell and Caldwell 1972, Taylor and Saayman 1973, Herman 1980, Richards et al. 1984,

76 Reiss and McCowan 1993) and conspecific sounds (Tyack 1986, Janik and Slater 1998, Janik

77 2000, Fripp et al. 2005). Initial examination of the BRS 07-08 Dtag sound recordings revealed

78 several instances in which, just after exposure to the MFA signal, false killer whales (Pseudorca

79 crassidens) produced whistles that sounded similar to the MFA to human listeners (see Fig. 1 for

80 an example). We therefore conducted a quantitative analysis to test whether delphinids exposed

81 to simulated MFA signals responded vocally to the MFA, specifically considering a response in

82 which animals produce a burst of whistles immediately after hearing an MFA sound, which are

83 more similar to the MFA than whistles produced at other times.

84 METHODS: DATA COLLECTION \& FIELD EXPERIMENTS

85 The data analyzed here were collected during BRS 07-08 at the U.S. Navy's Atlantic

86 Undersea Test and Evaluation Center (AUTEC) in the Tongue of the Ocean, Bahamas. During 
87 these experiments, beaked whales and delphinids were tagged with Dtags (Johnson and Tyack

88 2003, Johnson et al. 2006), which recorded sound (192 kHz sampling rate, overall frequency

89 response flat within $3 \mathrm{~dB}$ between 0.5 and $67 \mathrm{kHz}$ ) and movement data during exposure to a

90 simulated MFA sonar signal.

91 The MFA signal was a $1.4 \mathrm{~s}$ tonal signal with 3 parts: a $0.5 \mathrm{~s}$ upsweep from 3.1 to 3.2

$92 \mathrm{kHz}$, a $0.5 \mathrm{~s}$ tone at $3.3 \mathrm{kHz}$, a $0.1 \mathrm{~s}$ silence, and finally a $0.3 \mathrm{~s}$ tone at $3.4 \mathrm{kHz}$ (Fig. 1). During

93 each exposure experiment, the signal was transmitted every $25 \mathrm{~s}$, with a total of 30 to 44

94 transmissions per exposure. The initial sound source level (SL) was $160 \mathrm{~dB}$ re $1 \mu \mathrm{Pa}$ rms at $1 \mathrm{~m}$.

95 SL was increased by $3 \mathrm{~dB}$ with each successive ping to a maximum level of $211 \mathrm{~dB}$ re $1 \mu \mathrm{Pa}$ at 1

$96 \mathrm{~m}$.

97 A subset of the BRS data are considered here, including three datasets from tags placed

98 on a pilot whale (Globicephala macrorhynchus, gm07_229b), a false killer whale (Pseudorca

99 crassidens, pc08_272a), and a melon-headed whale (Peponocephala electra, pe08_273b).

100 Datasets were also available from another pilot whale (gm08_273a) and false killer whale

101 (pc08_270a), but those will not be considered in detail because the animals remained nearly

102 silent throughout the exposure, producing five and four whistles, respectively. Another pilot

103 whale (gm07_229a) was also tagged and exposed concurrently with gm07_229b, but since the

104 two datasets were not independent samples, 229b was selected arbitrarily for analysis and 229a

105 for exclusion.

106 Details of the tag deployments and controlled exposures of delphinids are presented in

107 Table 1, while more complete descriptions of the experimental protocol (Boyd et al. 2008) and

108 the tagging process (Madsen et al. 2005b) are available elsewhere.

109 METHODS: ACOUSTIC DATA PROCESSING 
110 We analyzed the time period from the beginning of the MFA exposure period until $25 \mathrm{~s}$

111 after the end of the final transmission. Start times of each whistle and each received MFA signal

112 were determined by inspection of spectrograms produced in Matlab (Mathworks, Natick, MA;

$113 \mathrm{nfft}=2048$, Hamming window, 50\% overlap). All whistles that were visible on the spectrogram

114 were included in the analysis, whether they were produced by the tagged whale or by others in its

115 group. Whistle contours were traced using a semi-automated custom Matlab algorithm. Briefly,

116 the operator clicked on a spectrogram to select the start, end, and several points along the whistle

117 contour. The software traced a smooth curve through the selected points (using the Matlab

118 function "pchip"), displaying results for operator approval. The lowest frequency contour

119 present in the whistle was traced, except in multi-voiced calls where the lowest component only

120 lasted for part of the whistle duration (in such cases, the next-highest-frequency contour that

121 lasted the full call duration was traced). Determination of which calls were overlapping or multi-

122 voiced was made based on relative amplitude and comparison to other calls (most multi-voiced

123 calls occurred many times in the dataset, while pairs of overlapping calls would be chance

124 events). Accuracy of all traced contours was verified by visual inspection of a plot in which the

125 traced contour was overlaid on the whistle spectrogram.

126 We calculated a similarity index (SI) between each whistle contour and the MFA signal

127 as a function of four measures: duration (absolute value of MFA duration - whistle duration),

128 mean frequency (absolute value of mean MFA frequency - mean whistle frequency), whistle

129 flatness ((Miksis et al. 2002), with flatter whistles considered more similar to the MFA), and

130 whistle frequency range (total frequency range covered by whistle divided by median frequency,

131 with smaller values considered more similar to MFA). These four metrics were computed,

132 scaled to range from 0 to 1 by dividing each whistle's score by the maximum observed value for 
133 that tag dataset. In cases where lower scores indicated higher similarity to the MFA sound, the

134 scaled values were subtracted from 1 so that higher scores indicated greater similarity to the

135 MFA. Finally, these scores were summed to obtain a SI value for each individual whistle.

136 METHODS: STATISTICAL ANALYSIS

137 All statistical tests were applied to each group of whales (that is, each Dtag recording)

138 separately. We used an overall significance threshold of $P=0.02(P=0.05$ with a Bonferroni

139 correction factor to account for the three groups tested). We tested for autocorrelation of inter-

140 whistle intervals and calculated Greenwood's test statistic (Greenwood 1946) to verify that

141 whistles occurred in clusters. To test for a correlation between whistle-MFA similarity and the

142 time since the last MFA reception, we fitted a straight line to a scatter plot of SI as a function of

143 time since the last MFA reception, then applied a rotation test (DeRuiter and Solow 2008), using

144 the line's slope as the test statistic. We compared the observed slope of the SI data with those

145 obtained in 100,000 random "rotations" of each dataset. Each rotated dataset was constructed by

146 randomly re-assigning the nominal start time of the exposure period, while maintaining the

147 whistle time-series, the spacing between MFA sounds, and the exposure duration. We chose

148 this test rather than a standard linear regression to account for autocorrelation and clustering in

149 the time series of SI scores caused by variations in call rates with behavior or by call-type

150 matching (Janik 2000, Miller et al. 2004).

151 We carried out a second analysis using a point-process time series model (Truccolo et al.

152 2005) to quantify temporal variation of whistle production rate. This model related whistle rate

153 to time since the most recent MFA reception, time since the first MFA reception, and number of

154 whistles occurring in the preceding time interval. For each group of whales, a whistle time series

155 (with value 1 at whistle start times and 0 at all other times) was constructed using $0.01 \mathrm{~s}$ time 
156 steps, equal to the time resolution of our spectrograms. These time series were then modeled

157 according to the equation

$158 \lambda\left(\mathrm{t}_{\mathrm{k}} \mid \mathrm{H}_{\mathrm{k}}\right)=\exp \left\{\mu+\beta_{1} \mathrm{~T}_{\mathrm{k}}+\beta_{2} \mathrm{~S}_{\mathrm{k}}+\beta_{3}\left(\mathrm{~N}_{\mathrm{k}}-\mathrm{N}_{(\mathrm{k}-\mathrm{w} / \Delta)}\right)\right\}$,

159 where $\lambda\left(t_{k} \mid H_{k}\right)$ is the conditional intensity function giving the probability of a whistle starting at

160 time interval $k\left(t_{k}\right)$, given the history up to that time point $\left(H_{k}\right) ; T_{k}$ is the time since the first MFA

161 reception; $S_{k}$ is the time since the most recent MFA reception; $\left(N_{k}-N_{(k-w / 4)}\right)$ is the number of

162 whistles that started in a $w$-second interval before time-step $k$ ( $\Delta$ being the time-step size, here

$1630.01 \mathrm{~s}$ ); and $\mu$ (the background whistle rate), $\beta_{1,}, \beta_{2}$, and $\beta_{3}$ are parameters to be estimated by the

164 model. The "preceding time interval" term accounts for clustering and is analogous to the

165 ensemble rates modeled by Truccolo et al. (2005). Intervals of 1, 5, 10, 20, 30, 40, 50, and $60 \mathrm{~s}$

166 were tested for each dataset. Akaike's information criterion (AIC) was used to select the optimal

167 preceding-interval duration and determine which terms to include in the model for each dataset,

168 including additional terms only if they decreased AIC by at least 2, but selecting the single

169 "preceding time interval" with minimal AIC in all cases. Models were fitted using generalized

170 linear modeling (GLM) methods in R (http://www.R-project.org).

171 We repeated the point-process analysis considering only MFA-like whistles - a subset of

172 whistles most similar to the MFA. Whistles scoring above the $80^{\text {th }}$ percentile for SI were

173 considered to be MFA-like; this choice of the $80^{\text {th }}$ percentile is relatively arbitrary, but statistical

174 inference regarding the relationship between MFA-like whistle rate and time since the last MFA

175 reception was the same for 7 other thresholds ranging from the $50^{\text {th }}$ to the $95^{\text {th }}$ percentiles (data

176 not shown).

177 RESULTS 
Figure 2 shows all traced whistle contours. The number of whistles detected during the

179 MFA exposure and contour-traced for further analysis was 466 for the false killer whales, 173

180 for the pilot whales, and 53 for the melon-headed whales (Table 2). Of these, 95, 114, and 11

181 respectively were classified as MFA-like. Figure 3 shows examples of the SI classification,

182 illustrating that lower-frequency, less-frequency modulated whistles were classed as MFA-like

183 while highly modulated, higher-frequency whistles had the lowest SI scores. The melon-headed

184 whales had fewer whistle contour types $(\sim 3)$ than the other groups, so absolute frequency and

185 duration of the whistles played a larger role in determining SI of that dataset.

186 For all three groups, whistle times were both clustered and auto-correlated (Table 2),

187 indicating the use of methods such as the rotation test and the point-process model which take

188 such clustering into account.

189 For the false killer whales, the correlation/rotation test indicated a slight negative

190 relationship between SI and time since last MFA reception, so whistles were most similar to the

191 MFA sound immediately after each MFA reception, then similarity declined until after the next

192 reception $(P=0.0041$, Fig. 4 , Table 2). Figure 2 also shows evidence of this trend, since there

193 are more unmodulated, lower-frequency whistles at short time delays after the MFA sound.

194 Other groups showed no significant trends $(P>0.02$, Fig. 4, Table 2$)$.

195 Point process analysis results for the false killer whale (pc08_272a) group confirmed the

196 rotation test findings, as both overall and "MFA-like" whistle rates were inversely proportional

197 to time elapsed since the last MFA reception (Fig. 4, Table 2). In other words, after each MFA

198 reception, the group increased whistle production rate and made more-MFA-like whistles. There

199 was also a slight reduction in the rate of MFA-like whistles, but not the overall whistle rate, as

200 overall time since start of exposure (and thus MFA received levels) increased (Fig. 4, Table 2). 
201 In contrast to the false killer whale pattern, there was an increase in overall whistle rate by the

202 melon-headed whales as a function of time since last MFA reception (that is, a transient

203 reduction in whistle rate immediately following each MFA reception); the pilot whales showed

204 no such trends (Table 2, Fig. 2). In all cases with adequate sample size $(n>11)$, the point process

205 models indicated a dependence of whistle rate at any given moment upon whistle rate in the

206 preceding $10-50 \mathrm{~s}$; they thus indicate the time scale over which individuals are modulating their

207 whistle rates in response to group whistling activity.

208 DISCUSSION

209 Results of the two independent statistical approaches applied in this study

210 (Correlation/Rotation Test and Point Process Method) consistently support the idea that a group

211 of false killer whales increased their whistle rate, and produced more MFA-like whistles, just

212 after hearing each of a series of MFA transmissions. Whistle production rate and whistle-MFA

213 similarity were both highest immediately following each individual MFA reception, then

214 declined over the $25 \mathrm{~s}$ period preceding the next MFA reception. This result is consistent with

215 previous anecdotal reports that delphinids whistle back at and imitate sonars and other active

216 acoustic devices (e.g., Hager 2008, S. Baumann-Pickering ${ }^{1}$, C. Clark, unpublished observations).

217 Our results complement those of Alves and colleagues, obtained during a study in which long-

218 finned pilot whales (Globicephala melas) underwent controlled exposure to military sonar

219 sounds. $^{2}$ Alves et al. found that some (but not all) pilot whale groups changed their call

220 production patterns during the exposure, increasing their production rate of calls with contours

\footnotetext{
${ }^{1}$ S. Baumann-Pickering, Marine Physical Laboratory, Whale Acoustics, Scripps Institution of Oceanography, 9500 Gilman Dr., La Jolla, CA 92093-0205. Personal Communication, 8/2010.

${ }^{2}$ A. Alves (Bute Building, University of St Andrews, St Andrews, Fife KY16 9TS, UK), R. Antunes,F.-P. A. Lam, P. Kvadsheim, and P. J. O. Miller. Manuscript in review entitled "Vocal matching of frequency-modulations of sonar signals by long-finned pilot whales (Globicephala melas)." Personal Communication, 5/2011.
} 
221 similar to those of the sonar stimuli. Our findings are also consistent with Rendell and Gordon

222 (1999), who reported increased whistle rates from a group of long-finned pilot whales

223 immediately following periodic receptions of 4 to $5 \mathrm{kHz}$ military sonar transmissions, although

224 these whales did not increase production rates of the whistle type most similar to the sonar

225 signal. Finally, the changes here observed in false killer whale whistle production patterns are

226 reminiscent of the call-type matching observed in vocal exchanges between socializing

227 bottlenose dolphins (Tursiops truncatus) (Janik 2000), killer whales (Orcinus orca) (Miller et al.

228 2004), and pilot whales (Sayigh et al. in press).

229 In contrast to the false killer whales, melon-headed whales had lower whistle rates

230 immediately after each individual MFA reception, while pilot whales showed no trends.

231 Previous research has shown that whistle production rates in pilot whales and other delphinids

232 vary greatly with behavioral state (Taruski 1979, Weilgart and Whitehead 1990, Watwood et al.

233 2005, Quick and Janik 2008). Given the available data, it is not possible to determine whether

234 this observed variability of responses is rooted in differences between individuals/groups,

235 species, or behavioral/social contexts. However, in a similar study of long-finned pilot whale

236 whistle production during mid-frequency sonar exposure, only about $25 \%$ of observed groups

237 matched sounds as observed here. ${ }^{2}$ The whistle repertoire of pilot whales in particular is

238 extremely varied and encompasses the frequency range of the MFA signal, so the differences

239 between their responses and those of the false killer whales are not likely caused by

240 physiological limitations.

241 The function of the observed responses to the MFA sound is unknown. Delphinid

242 whistles are used for communication, most often in affiliative contexts (Tyack 1998). The false

243 killer whales made more MFA-like whistles just after MFA signal reception, suggesting that they 
244 may have been roughly imitating the sonar or incorporating some features of the MFA sound

245 into their whistles. The hypothesized functions of such acoustic matching by animals vary

246 widely, and include the development of varied repertoires and the use of learned calls to indicate

247 identity or group membership (Krebs and Kroodsma 1980, Tyack 2008). Acoustic matching

248 sometimes plays a role in deterring predators, raising an alarm, or attracting prey (Rowe et al.

249 1986, Chu 2001, Goodale and Kotagama 2006, Barber and Conner 2007, Marshall and Hill

250 2009). In some social interactions, particularly among songbirds, imitation or matching of a

251 conspecific's call type can function as a challenge or threat (e.g., Krebs et al. 1981, Arak 1983,

252 Searcy and Beecher 2009). However, for many species, acoustic matching is an affiliative

253 gesture, with convergence of call characteristics among members of a social group helping to

254 build and sustain social bonds (reviewed by Tyack 2008).

255 The observed behavior of the false killer whales in response to the MFA might thus be an

256 adaptive mechanism to expand the vocal repertoire, an affiliative or agonistic response, or a

257 predator-avoidance response. We must also consider the possibility that the false killer whales

258 were changing their call production patterns in response to the MFA sound, but that the increased

259 similarity of the two sounds was coincidental. Previous work has observed that bottlenose

260 dolphin whistle rates increase and whistle modulation decreases when they are under stress

261 (Caldwell et al. 1970, Esch et al. 2009), when ambient noise is high (Morisaka et al. 2005), or as

262 vessels approach (Buckstaff 2004). This type of reaction could explain our results if false killer

263 whales respond to stress and/or noise as dolphins do, and if such changes occur and then decline

264 over periods as short as the 25 second intervals studied here.

265

The observed whistle response of false killer whales to MFA clearly differs from some

266 commonly discussed reactions to anthropogenic noise, such as avoidance responses and silencing 
267 (although we did see a very subtle silencing effect in the melon-headed whale dataset). For

268 highly social delphinid species that communicate extensively using sound and rely on group

269 defenses rather than acoustic or behavioral crypsis to guard against predation and other threats,

270 vocal responses and changes in group cohesion or group behavior may be the dominant type of

271 reaction to such stimuli. The methods presented here, which allow detailed quantitative analysis

272 of call rates including the effects of clustering and external covariates, offer a promising avenue

273 toward greater understanding of delphinid social-acoustic behavior in the presence and absence

274 of anthropogenic sounds.

275

276 ACKNOWLEDGEMENTS

277 The authors are extremely grateful to the science party and crew of BRS 07-08 and collaborators 278 at AUTEC, and sincerely thank everyone who contributed to this large team effort. John Buck

279 and Erik Siggelkoe provided Matlab code for dynamic time warping (used in a previous version

280 of this paper). Andy Solow provided statistical advice on an early version of this analysis, and

281 multiple anonymous reviewers provided comments on earlier versions of the paper. This

282 research was funded by the US Office of Naval Research, the US Strategic Environmental

283 Research and Development Program, the Environmental Readiness Division of the US Navy, the

284 US Chief of Naval Operations Submarine Warfare Division (Undersea Surveillance), the US

285 National Oceanic and Atmospheric Administration (National Marine Fisheries Service, Office of

286 Science and Technology) and the Joint Industry Program on Sound and Marine Life of the

287 International Association of Oil and Gas Producers. The research permits were issued to J.

288 Boreman and B. Southall (US NMFS 1121-1900), P. Tyack (US NMFS 981-1578), Bahamas

289 Marine Mammal Research Organisation (Bahamas permit \#01/09) and I. Boyd (Bahamas permit 
$290 \# 02 / 07$ and \#02/08). Experiments were approved by the WHOI and BMMRO Institutional

291 Animal Care and Use Committees.

292

293 LITERATURE CITED

294 Aguilar Soto, N., M. P. Johnson, P. T. Madsen, P. L. Tyack, A. Bocconcelli, and J. F. Borsani.

295 2006. Does intense ship noise disrupt foraging in deep-diving Cuvier's beaked whales

296 (Ziphius cavirostris)? Marine Mammal Science 22:690-699.

297 Arak, A. 1983. Vocal interactions, call matching and territoriality in a Sri Lankan treefrog, 298 Philautus leucorhinus (Rhacophoridae). Animal Behaviour 31:292-302.

299 Balcomb, K. C. III, and D. E. Claridge. 2001. A mass stranding of cetaceans caused by naval $300 \quad$ sonar in the Bahamas. Bahamas Journal of Science 8:1-12.

301 Barber, J. R., and W. E. Conner. 2007. Acoustic mimicry in a predator-prey interaction.

302 Proceedings of the National Academy of Sciences 104: 9331-9334.

303 Barlow, J., and G. A. Cameron. 2003. Field experiments show that acoustic pingers reduce 304 marine mammal bycatch in the California drift gill net fishery. Marine Mammal Science $305 \quad 19: 265-283$.

306 Boyd, I. L., D. E. Claridge, C. Clark, B. L. Southall, and P. L. Tyack. 2008. Behavioral Response 307 Study-2007 (BRS-07) Cruise Report (unpublished). Available online at www.sea308 inc.net/resources/brs_07finalcruisereport.pdf(accessed 5/11/2011).

309 Buckstaff, K. C. 2004. Effects of watercraft noise on the acoustic behavior of bottlenose 310 dolphins, Tursiops truncatus, in Sarasota Bay, Florida. Marine Mammal Science 20:709$311 \quad 725$. 
312 Caldwell, D. K., and M. C. Caldwell. 1972. Vocal mimicry in the whistle mode in the Atlantic 313 bottlenosed dolphin. Cetology 9:1-8.

314 Caldwell, M. C., D. K. Caldwell, and R. H. Turner. 1970. Statistical analysis of the signature

315 whistle of an Atlantic bottlenosed dolphin with correlations between vocal changes and 316 level of arousal. Los Angeles County Museum of Natural History Foundation, Technical 317 Report no. 8.31 pp.

318 Carretta, J. V., J. Barlow, and L. Enriquez. 2008. Acoustic pingers eliminate beaked whale 319 bycatch in a gill net fishery. Marine Mammal Science 24:956-961.

320 Chu, M. 2001. Vocal mimicry in distress calls of Phainopeplas. The Condor 103:389-395.

321 Cox, T. M., T. J. Ragen, A. J. Read, et al. 2006. Understanding the impacts of anthropogenic 322 sound on beaked whales. Journal of Cetacean Research and Management 7:177-187.

323 DeRuiter, S. L., and A. R. Solow. 2008. A rotation test for behavioural point-process data. $324 \quad$ Animal Behaviour 76:1429-1434.

325 Esch, H. C., L. S. Sayigh, J. E. Blum, and R. S. Wells. 2009. Whistles as potential indicators of 326 stress in bottlenose dolphins (Tursiops truncatus). Journal of Mammalogy 90:638-650.

327 Evans, D.L. and G. R. England. 2001. Joint Interim Report, Bahamas marine mammal stranding 328 event of $14-16$ March 2000. Unpublished report released by the U.S. Department of

329 Commerce and the Secretary of the Navy, vi $+59 \mathrm{pp}$. Available from: http://www.nmfs.noaa.gov/pr/acoustics/reports.htm

331 Fernández, A., J. F. Edwards, F. Rodríguez, A. Espinosa de los Monteros, P. Herráez, P. Castro, 332 J. R. Jaber, V. Martín, and M. Arbelo. 2005. "Gas and fat embolic syndrome” involving a mass stranding of beaked whales (Family Ziphiidae) exposed to anthropogenic sonar $334 \quad$ signals. Veterinary Pathology 42:446-457. 
335 Filadelfo, R., J. Mintz, E. Michlovich, A. D. D’Amico, P. L. Tyack, and D. R. Ketten. 2009.

336 Correlating military sonar use with beaked whale mass strandings: what do these

337 historical data show? Aquatic Mammals 35:435-444.

338 Frantzis, A. 1998. Does acoustic testing strand whales? Nature 392:29.

339 Fripp, D., C. Owen, E. Quintana-Rizzo, A. Shapiro, K. Buckstaff, K. Jankowski, R. Wells, and

340 P. L. Tyack. 2005. Bottlenose dolphin (Tursiops truncatus) calves appear to model their

341 signature whistles on the signature whistles of community members. Animal Cognition

$342 \quad 8: 17-26$.

343 Goodale, E., and S. W. Kotagama. 2006. Context-dependent vocal mimicry in a passerine bird.

344 Proceedings of the Royal Society B - Biological Sciences 273:875-880.

345 Greenwood, M. 1946. The statistical study of infectious diseases. Journal of the Royal Statistical $346 \quad$ Society 109:85-110.

347 Herman, L. M. 1980. Cognitive characteristics of dolphins. Pages 363-429 in Cetacean Behavior:

348 Mechanisms and functions (L.M. Herman, Ed.). New York, NY: Wiley Interscience.

349 Hager, C. A. 2008. Assessment of the performance of the nearbottom hydrophones of the U.S.

$350 \quad$ Navy Southern California offshore range in detecting, localizing and reconstructing 10-

$35120 \mathrm{kHz}$ odontocete whistles. PhD Thesis, Naval Postgraduate School, Monterey, CA. 81

$352 \quad$ pp.

353 Hildebrand, J. A. 2005. Impacts of Anthropogenic Sound. Pages 101-124 in J. E. I. Reynolds, W.

354 F. Perrin, R. R. Reeves, S. Montgomery, and T. J. Ragen, eds. Marine mammal research:

355 Conservation beyond crisis. Johns Hopkins University Press, Baltimore, MD. 
356 Houser, D. S., R. Howard, and S. Ridgway. 2001. Can diving-induced tissue nitrogen supersaturation increase the chance of acoustically driven bubble growth in marine mammals? Journal of Theoretical Biology 213:183-195.

359 Janik, V. M. 2000. Whistle matching in wild bottlenose dolphins (Tursiops truncatus). Science 289:1355-1357.

361 Janik, V. M., and P. J. B. Slater. 1998. Context-specific use suggests that bottlenose dolphin $362 \quad$ signature whistles are cohesion calls. Animal Behaviour 56:829-838.

363 Johnson, M. P., P. T. Madsen, W. M. X. Zimmer, N. Aguilar de Soto, and P. L. Tyack. 2006.

$364 \quad$ Foraging Blainville's beaked whales (Mesoplodon densirostris) produce distinct click 365 types matched to different phases of echolocation. Journal of Experimental Biology $366 \quad 209: 5038-5050$.

367 Johnson, M. P., P. T. Madsen, W. M. X. Zimmer, N. Aguilar de Soto, and P. L. Tyack. 2004.

368 Beaked whales echolocate on prey. Biology Letters 271:S383-S386.

369 Johnson, M. P., and P. L. Tyack. 2003. A digital acoustic recording tag for measuring the response of wild marine mammals to sound. IEEE Journal of Oceanic Engineering 28:312.

372 Krebs, J. R., R. Ashcroft, and K. V. Orsdol. 1981. Song matching in the great tit Parus major L. $373 \quad$ Animal Behaviour 29:918-923.

374 Krebs, J. R., and D. E. Kroodsma. 1980. Repertoires and geographical variation in bird song. 375 Pages 143-177 in J. S. Rosenblatt, ed. Advances in the study of behavior. Academic $376 \quad$ Press, New York, NY. 
377 Kvadsheim, P., F.-P. Lam, P. J. O. Miller, et al. 2009. Cetaceans and naval sonar - the 3S-2009

378

379

380 381

382

383

384

385

386

387

388

389

390

391

392

393

394

395

396

397

398

399

cruise report. Forsvarets forskningsinstitutt, Kjeller, Norway. 133 pp. Available online at http://rapporter.ffi.no/rapporter/2009/01140.pdf (accessed 5/11/2011).

Lesage, V., C. Barrette, M. C. S. Kingsley, and B. Sjare. 1999. The effect of vessel noise on the vocal behavior of belugas in the St. Lawrence River estuary, Canada. Marine Mammal Science 15:65-84.

Madsen, P. T., D. A. Carder, K. Beedholm, and S. H. Ridgway. 2005a. Porpoise clicks from a sperm whale nose - Convergent evolution of $130 \mathrm{kHz}$ pulses in toothed whale sonars? Bioacoustics 15:195-206.

Madsen, P. T., M. P. Johnson, N. Aguilar de Soto, W. M. X. Zimmer, and P. L. Tyack. $2005 b$. Biosonar performance of foraging beaked whales (Mesoplodon densirostris). Journal of Experimental Biology 208:181-194.

Marshall, D. C., and K. B. Hill. 2009. Versatile aggressive mimicry of cicadas by an Australian predatory katydid. PLoS ONE 4:e4185.

Miksis, J. L., P. L. Tyack, and J. R. Buck. 2002. Captive dolphins, Tursiops truncatus, develop signature whistles that match acoustic features of human-made model sounds. Journal of the Acoustical Society of America 112:728-739.

Miller, P. J. O., A. D. Shapiro, P. L. Tyack, and A. R. Solow. 2004. Call-type matching in vocal exchanges of free-ranging resident killer whales, Orcinus orca. Animal Behaviour 67:1099-1107.

Morisaka, T., and R. C. Connor. 2007. Predation by killer whales (Orcinus orca) and the evolution of whistle loss and narrow-band high frequency clicks in odontocetes. Journal of Evolutionary Biology 20:1439-1458. 
400 Morisaka, T., M. Shinohara, F. Nakahara, and T. Akamatsu. 2005. Effects of ambient noise on 401 the whistles of Indo-Pacific bottlenose dolphin populations. Journal of Mammalogy $86: 541-546$.

403 National Research Council. 2005. Marine mammal populations and ocean noise: Determining 404 when noise causes biologically significant effects. Committee on Characterizing 405 Biologically Significant Marine Mammal Behavior, Ocean Studies Board, Division on 406 Earth and Life Studies, National Research Council, The National Academies Press, 407 Washington, DC.142 pp.

408 Parsons, E. C. M., S. J. Dolman, A. J. Wright, N. A. Rose, and W. C. G. Burns. 2008. Navy 409 sonar and cetaceans: Just how much does the gun need to smoke before we act? Marine $410 \quad$ Pollution Bulletin 56:1248-1257.

411 Quick, N. J., and V. M. Janik. 2008. Whistle rates of wild bottlenose dolphins (Tursiops 412 truncatus): Influences of group size and behavior. Journal of Comparative Psychology $413 \quad 122: 305-311$.

414 Reiss, D., and B. McCowan. 1993. Spontaneous vocal mimicry and production by bottlenose 415 dolphins (Tursiops truncatus): Evidence for vocal learning. Journal of Comparative $416 \quad$ Psychology 107:301-312.

417 Rendell, L. E., and J. C. D. Gordon. 1999. Vocal response of long-finned pilot whales 418 (Globicephala melas) to military sonar in the Ligurian Sea. Marine Mammal Science $419 \quad 15: 198-204$.

420 Richards, D. G., J. P. Wolz, and L. M. Herman. 1984. Vocal mimicry of computer-generated 421 sounds and vocal labeling of objects by a bottlenosed dolphin, Tursiops truncatus, $422 \quad$ Journal of Comparative Psychology 98:10-28. 
423 Rowe, M. P., R. G. Coss, and D. H. Owings. 1986. Rattlesnake rattles and burrowing owl lines: a $424 \quad$ case of acoustic Batesian mimicry. Ethology 72:53-71.

425 Sayigh, L. S., Quick, N. J., Hastie, G., Janik, V. M., Boyd, I. L., Claridge, D. E., Clark, C., 426 Moretti, David J., Southall, Brandon L., and Tyack, Peter L. (in press). Repeated calls in 427 short-finned pilot whales, Globicephala macrorhynchus. Marine Mammal Science (in $428 \quad$ press).

429 Searcy, W. A., and M. D. Beecher. 2009. Song as an aggressive signal in songbirds. Animal $430 \quad$ Behaviour 78:1281-1292.

431 Simmonds, M. P., and L. F. Lopez-Jurado. 1991. Whales and the military. Nature 337:448.

432 Southall, B. L., A. E. Bowles, W. T. Ellison, et al. 2007. Marine mammal noise exposure 433 criteria: Initial scientific recommendations. Aquatic Mammals 33:411-521.

434 Taruski, A. G. 1979. The whistle repertoire of the north Atlantic pilot whale (Globicephala 435 melaena) and its relationship to behavior and environment. Pages 345-367 in H. E. Winn 436 and B. L. Olla, eds. Behavior of marine animals. Plenum, New York, NY.

437 Taylor, C. K., and Saayman, G. (1973). Imitative behavior by Indian Ocean bottlenose dolphins 438 (Tursiops aduncus) in captivity. Behaviour, 44, 286-298.

439 Truccolo, W., U. T. Eden, M. R. Fellows, J. P. Donoghue, and E. N. Brown. 2005. A point 440 process framework for relating neural spiking activity to spiking history, neural 441 ensemble, and extrinsic covariate effects. Journal of Neurophysiology 93:1074-1089.

442 Tyack, P. 1986. Whistle repertoires of two bottlenosed dolphins, Tursiops truncatus: Mimicry of 443 signature whistles? Behavioral Ecology and Sociobiology 18:251-257. 
444 Tyack, P. L. 1998. Acoustic communication under the sea. Pages 163-220 in S. L. Hopp, M. J.

445 Owren, and C. S. Evans, eds. Animal acoustic communication: Sound analysis and

446 research methods. Springer Verlag, New York, NY.

447 Tyack, P. L. 2000. Functional aspects of cetacean communication. Pages 270-307 in J. Mann, R.

448 Connor, P. L. Tyack, and H. Whitehead, eds. Cetacean societies: Field studies of dolphins 449 and whales. University of Chicago Press, Chicago, IL.

450 Tyack, P. L. 2008. Convergence of calls as animals form social bonds, active compensation for noisy communication channels, and the evolution of vocal learning in mammals. Journal of Comparative Psychology 122:319-331.

453 Tyack, P. L., M. P. Johnson, N. Aguilar de Soto, A. Sturlese, and P. T. Madsen. 2006. Extreme 454 diving of beaked whales. Journal of Experimental Biology 209:4238-4253.

455 Tyack, P. L., W. M. X. Zimmer, D. Moretti, et al. 2011. Beaked whales respond to simulated and 456 actual navy sonar. PloS One 6:e17009.

457 Watwood, S. L., E. C. G. Owen, P. L. Tyack, and R. S. Wells. 2005. Signature whistle use by 458 temporarily restrained and free-swimming bottlenose dolphins, Tursiops truncatus. $459 \quad$ Animal Behaviour 69:1373-1386.

460 Weilgart, L., and H. Whitehead. 1990. Vocalizations of the North Atlantic pilot whale 461 (Globicephala melas) as related to behavioral contexts. Behavioral Ecology and $462 \quad$ Sociobiology 26:399-402.

463 Zimmer, W. M. X., M. P. Johnson, P. T. Madsen, and P. L. Tyack. 2005. Echolocation clicks of 464 free-ranging Cuvier's beaked whales (Ziphius cavirostris). Journal of the Acoustical $465 \quad$ Society of America 117:3919-3927. 
Authors' Final Draft. Published version at DOI: 10.1111/j.1748-7692.2012.00587.x

466 Zimmer, W. M. X., and P. L. Tyack. 2007. Repetitive shallow dives pose decompression risk in 467 deep-diving beaked whales. Marine Mammal Science 23:888-925.

468 


\section{TABLES}

470 Table 1. Dtag deployments and MFA sonar controlled exposure experiments on delphinids during BRS 07-08.

\begin{tabular}{|c|c|c|c|c|c|c|}
\hline Tag ID & Species & Date & $\begin{array}{l}\text { Time (tag } \\
\text { on to tag } \\
\text { off, local } \\
\text { time) }\end{array}$ & $\begin{array}{l}\text { MFA exposure } \\
\text { start-end (local } \\
\text { time) }\end{array}$ & $\begin{array}{c}\text { Number of MFA } \\
\text { transmissions }\end{array}$ & $\begin{array}{c}\text { Received } \\
\text { Level (dB re } \\
1 \mu \text { Pa peak) }\end{array}$ \\
\hline gm07_229b & Pilot Whales & $\begin{array}{c}17 \text { Aug } \\
2007\end{array}$ & $1415-1728$ & $1458-1606^{*}$ & 44 & $112-129$ \\
\hline gm08_273a & Pilot Whales & $\begin{array}{l}29 \text { Sept } \\
2008\end{array}$ & $1022-1640$ & $1338-1351$ & 30 & $109-153$ \\
\hline pc08_270a & $\begin{array}{c}\text { False Killer } \\
\text { Whales }\end{array}$ & $\begin{array}{c}26 \mathrm{Sept} \\
2008\end{array}$ & $0821-1319$ & $1254-1306$ & 31 & $122-158$ \\
\hline pc08_272a & $\begin{array}{c}\text { False Killer } \\
\text { Whales }\end{array}$ & $\begin{array}{c}28 \text { Sept } \\
2008\end{array}$ & $1704-2328$ & $1732-1744$ & 30 & $116-161$ \\
\hline pe08_273b & $\begin{array}{l}\text { Melon- } \\
\text { Headed } \\
\text { Whales }\end{array}$ & $\begin{array}{c}29 \mathrm{Sept} \\
2008\end{array}$ & $1333-1512$ & $1338-1349$ & 30 & $109-144$ \\
\hline
\end{tabular}

471 *The exposure was suspended from 1502-1552 due to the presence of whales less than 1,000 $\mathrm{m}$ from the sound source. 
472 Table 2. Statistical results (model parameter values and p-values). Gray shading indicates results that were not statistically significant

473 at the $\mathrm{p}<0.02$ level. $\triangle \mathrm{AIC}$ is the difference between the AIC of the best model and the model with the next-lowest AIC; the subscripted

$474+,-$, or $\mathbf{0}$ indicates that the number of parameters in the next-best model was more, fewer, or the same (i.e., a different value for lag time).

\begin{tabular}{|c|c|c|c|}
\hline & gm07_229b & pc08_272a & pe08_273b \\
\hline Species & $\begin{array}{c}\text { Pilot Whales } \\
\text { (Globicephela macrorhynchus) }\end{array}$ & $\begin{array}{c}\text { False Killer Whales (Pseudorca } \\
\text { crassidens) }\end{array}$ & $\begin{array}{l}\text { Melon-headed Whales } \\
\text { (Peponocephala electra) }\end{array}$ \\
\hline $\begin{array}{l}\text { Number of whistles } \\
\text { (N MFA-like) }\end{array}$ & $173(114)$ & $466(96)$ & $53(11)$ \\
\hline $\begin{array}{l}\text { SI Correlation/Rotation } \\
\text { Test: Fitted Model (P- } \\
\text { value) }{ }^{1}\end{array}$ & $\begin{array}{l}\mathrm{SI}=2.0+0.0010 \mathrm{~S}_{\mathrm{k}} \\
(0.58)\end{array}$ & $\begin{aligned} \mathrm{SI}= & 2.1-0.015 \mathrm{~S}_{\mathrm{k}} \\
& (0.0041)\end{aligned}$ & $\begin{array}{c}\mathrm{SI}=2.1-0.0089 \mathrm{~S}_{\mathrm{k}} \\
(0.17)\end{array}$ \\
\hline $\begin{array}{l}\text { All Whistles: Fitted } \\
\text { Point Process Model } \\
\text { (parameter P-values) } \\
(\Delta \text { AIC) }\end{array}$ & $\begin{array}{c}\lambda\left(\mathrm{t}_{\mathrm{k}} \mid \mathrm{H}_{\mathrm{k}}\right)=\exp \left\{-6.9+0.22\left(\mathrm{~N}_{\mathrm{k}}-\mathrm{N}_{(\mathrm{k}-10 / \Delta)}\right)\right\} \\
\left(<2 \times 10^{-16},<2 \times 10^{-16}\right)\left(-2.7_{0}\right)\end{array}$ & $\begin{array}{c}\lambda\left(\mathrm{t}_{\mathrm{k}} \mid \mathrm{H}_{\mathrm{k}}\right)=\exp \left\{-5.5-0.42 \mathrm{~S}_{\mathrm{k}}+\right. \\
\left.0.041\left(\mathrm{~N}_{\mathrm{k}}-\mathrm{N}_{(\mathrm{k}-30 / \Delta)}\right)\right\} \\
\left(<2 \times 10^{-16}, 2.4 \times 10^{-10},<2 \times 10^{-16}\right)\left(-3.0_{0}\right)\end{array}$ & $\begin{array}{c}\lambda\left(\mathrm{t}_{\mathrm{k}} \mid \mathrm{H}_{\mathrm{k}}\right)=\exp \left\{-8.6+0.055 \mathrm{~S}_{\mathrm{k}}+\right. \\
\left.0.19\left(\mathrm{~N}_{\mathrm{k}}-\mathrm{N}_{(\mathrm{k}-40 / \Delta \Delta)}\right)\right\} \\
\left(<2 \times 10^{-16}, 0.0068,0.00014\right)(- \\
\left.0.8_{0}\right)\end{array}$ \\
\hline $\begin{array}{l}\text { MFA-like Whistles: } \\
\text { Fitted Point Process } \\
\text { Model (parameter P- } \\
\text { values) ( } \Delta \mathrm{AIC})\end{array}$ & $\begin{array}{c}\lambda\left(\mathrm{t}_{\mathrm{k}} \mid \mathrm{H}_{\mathrm{k}}\right)=\exp \left\{-7.2+0.27\left(\mathrm{~N}_{\mathrm{k}}-\mathrm{N}_{(\mathrm{k}-10 / \Delta)}\right)\right\} \\
\left(<2 \times 10^{-16}, 2.2 \times 10^{-12}\right)\left(-1.4_{+}\right)\end{array}$ & $\begin{aligned} & \lambda\left(\mathrm{t}_{\mathrm{k}} \mid \mathrm{H}_{\mathrm{k}}\right)=\exp \left\{-5.3-0.0015 \mathrm{~T}_{\mathrm{k}}-0.10 \mathrm{~S}_{\mathrm{k}}\right. \\
&\left.+0.044\left(\mathrm{~N}_{\mathrm{k}}-\mathrm{N}_{(\mathrm{k}-50 / \Delta)}\right)\right\} \\
&\left(<2 \times 10^{-16}, 7.7 \times 10^{-11}, 0.0055\right)\left(-0.4_{0}\right)\end{aligned}$ & $\begin{array}{l}\lambda\left(\mathrm{t}_{\mathrm{k}} \mid \mathrm{H}_{\mathrm{k}}\right)=\exp \{-9.1\} \\
\left(<2 \times 10^{-16}\right)\left(-0.2_{+}\right)\end{array}$ \\
\hline
\end{tabular}




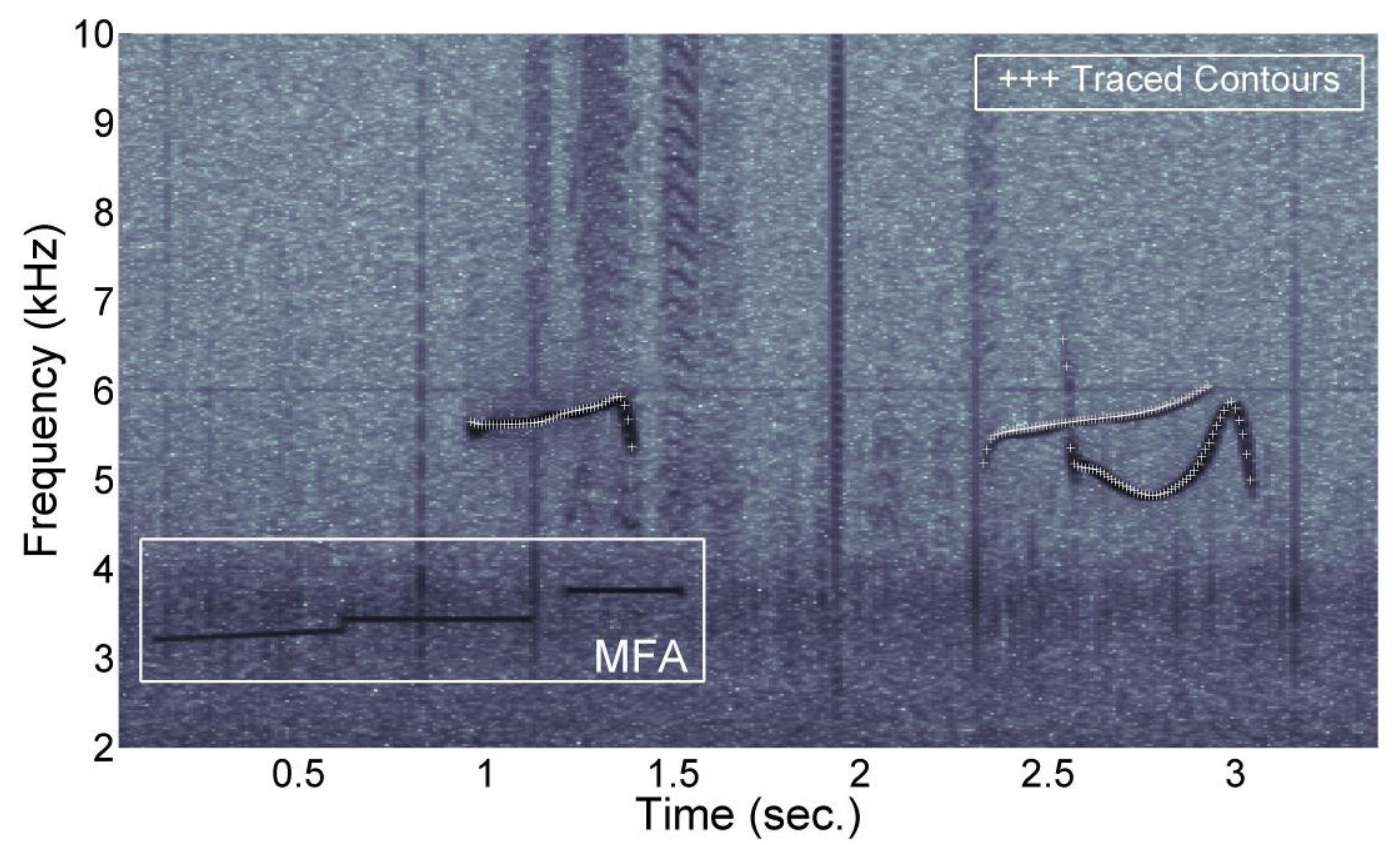

477 Figure 1. Spectrogram of Dtag acoustic data, showing the MFA signal (inside white box), as well 478 as several false killer whale whistles and their traced contours (white crosses).

479
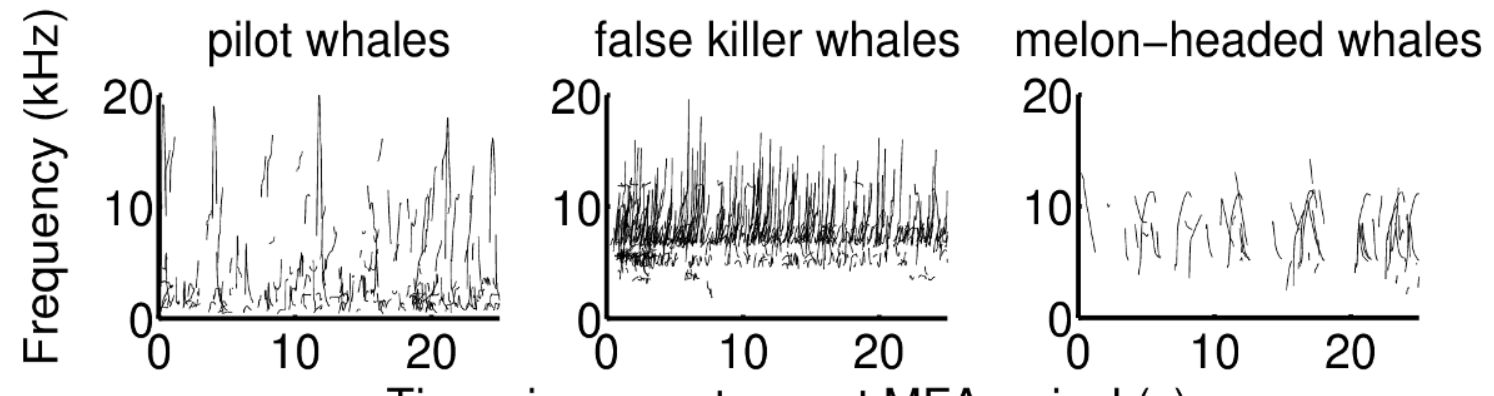

481 Figure 2. All whistle contours for pilot whales (gm07_229b), false killer whales (pc08_272a),

482 and melon-headed whales (pe08_273b), plotted as a function of time since the most recent MFA 483 arrival. 


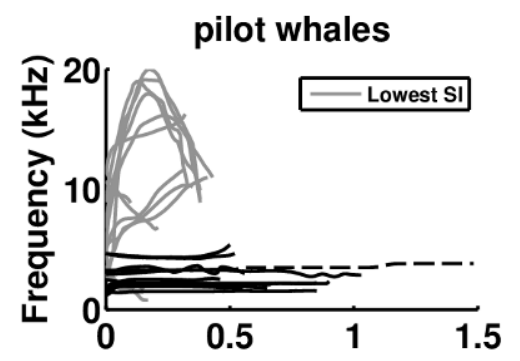

486 Figure 3. Most and least MFA-like whistle contours produced by pilot whales (gm07_229b),

487 false killer whales (pc08 272a), and melon-headed whales (pe08 273b). Grey traces show the 488 contours with the lowest SI (least MFA-like), and black traces the contours with highest SI (most 489 MFA-like). In each case, 15 traces of each type are plotted, except that only the 11 traces with 490 highest SI were plotted for the melon-headed whales (since only those 11 met the criterion for 491 being "MFA-like"). Dotted lines show the MFA contour.
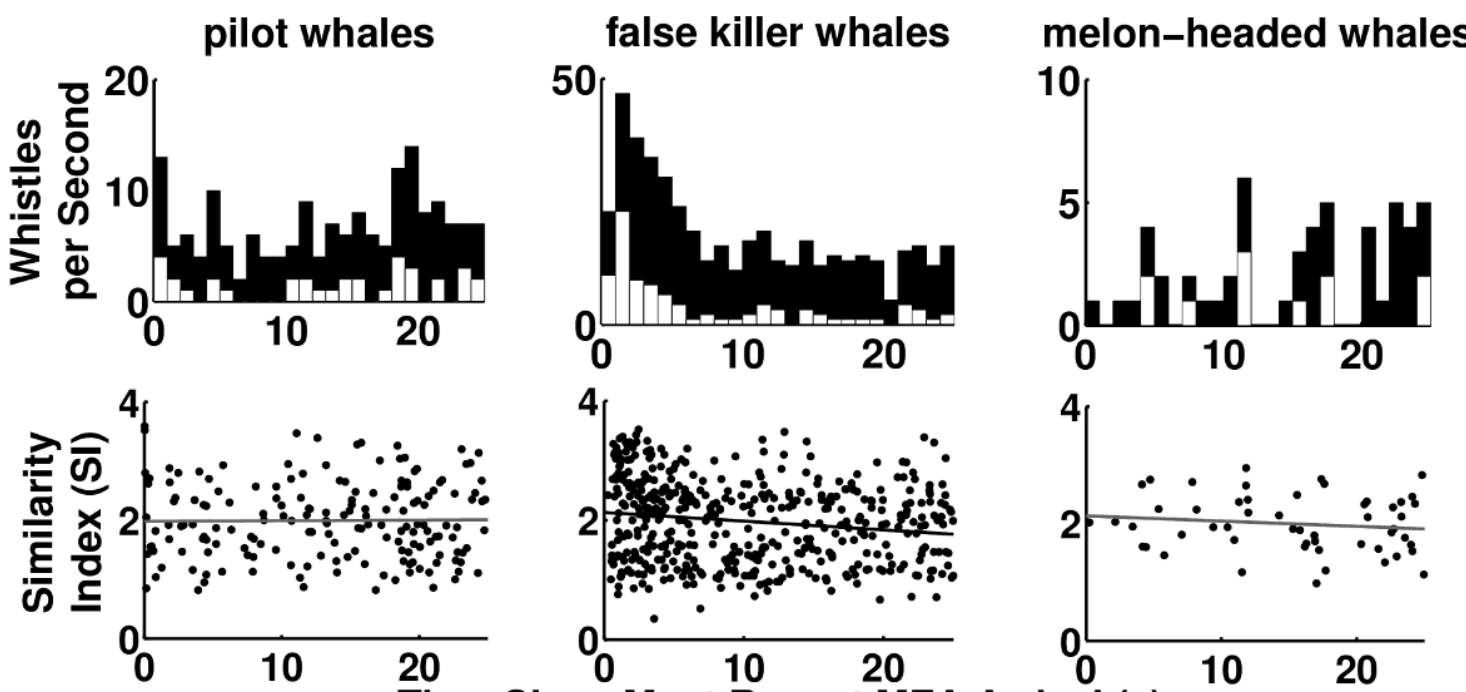

492 Time Since Most Recent MFA Arrival (s)

493 Figure 4. Patterns in whistle production in relation to time since the most recent MFA arrival.

494 Upper panels show whistle rate as a function of time since most recent MFA arrival, with the full 495 whistle dataset in black and only MFA-like whistles in white. Lower panels show Similarity 
Authors' Final Draft. Published version at DOI: 10.1111/j.1748-7692.2012.00587.x

496 Index as a function of time since the most recent MFA arrival. Dots show SI values for traced

497 whistle contours, grey lines show regression lines (not significant at the $P=0.02$ level), and the 498 black line is a regression line $(P=0.0041)$. 